\title{
Effect of ABO Blood Group on Blood Pressure Indices among Apparently Healthy Young Adults of Yoruba Ethnicity in Ile-Ife
}

\section{Asafa MA ${ }^{1 *}$, Ogunlade $\mathrm{O}^{1}$ and Bolarinwa RA ${ }^{2}$}

${ }^{1}$ Department of Physiological Sciences, Obafemi Awolowo University, Ile-Ife, Nigeria

${ }^{2}$ Department of Haematology and Immunology, Obafemi Awolowo University, Ile-Ife, Nigeria

\begin{abstract}
Background: This study evaluated the effects of $A B O$ blood groups on blood pressure indices.

Materials and methods: Eighty apparently healthy young adults between the ages of 18 and 40 years were purposively selected for the study. Twenty participants of blood group $A B$ were first identified through mass blood group screening process and 20 age and sex-matched participants each of the other three blood groups were also selected for the study. Two millilitres of venous blood was obtained from superficial cubital vein of each participant into a Sodium Ethylene Diamine Tetra-acetic Acid (EDTA) anticoagulant bottle for blood grouping following standard procedure using anti-sera $\mathrm{A}, \mathrm{B}$ and $\mathrm{AB}$. Blood pressure was measured in sitting position after 5 minutes of rest with digital sphygmomanometer (Omron) and the BP indices were derived from systolic, diastolic and pulse rate. Comparison of means of parameters among the four blood groups was done using Analysis of Variance (ANOVA) and Duncan Post-hoc test. A $p$ value of $<0.05$ was taken as statistically significant.
\end{abstract}

Results: The highest mean systolic, diastolic blood pressure, heart rate, mean arterial blood pressure and rate pressure product were found in blood group $O$ while the highest mean pulse pressure was found in blood group $A B$. The effects of $A B O$ blood group on blood pressure and its indices were not statistically significant. This study showed that $A B O$ blood group system does not significantly affect blood pressure indices.

Keywords: ABO blood group; Blood pressure indices; Young adults; Yoruba ethnicity

\section{Introduction}

Landsteiner discoveres three blood groups A, B, and O in 1900 [1]. Identification $\mathrm{AB}$ was done in 1902 by Decastello and Struli [2]. ABO blood group system was the first to be described among other blood group systems and still the most significant in transfusion medicine [3]. ABO blood group is genetically determined and plays role in the development of certain genetic disorders [4]. It is an easily accessible genetic make-up that has been linked up with some diseases [5-7]. The importance of $\mathrm{ABO}$ blood group system in blood transfusion had already been established [4]. Blood pressure (BP) is an important cardiovascular parameter being one of the four main vital signs routinely checked by medical professionals and health care provider [8]. The known risk factors for cardiovascular diseases are tobacco use, physical inactivity, dietary factors, alcohol abuse and genetics [9]. Among cardiovascular diseases, the most common in Black population is the hypertension and its complications [10]. Hypertension can be defined according to the Seventh Report of the Joint National Committee on Prevention, Detection, Evaluation, and Treatment of High Blood Pressure (JNC 7) as persistent elevation of systemic arterial blood pressure [11]. The diagnosis of hypertension is made when the blood pressure is greater or equal to $140 \mathrm{mmHg}$ and or $90 \mathrm{mmHg}$ on two or more occasions [11]. Most of the blood group studies on blood pressure have been on adult population with already established hypertension [12]. This study assessed the effect of ABO blood group on blood pressure and its indices among apparently healthy young adults of Yoruba Ethnicity.

\section{Materials and Methods}

This study was carried out at the University Health Centre and the Department of Physiological Sciences, Obafemi Awolowo University, Ile-Ife. It was a cross-sectional descriptive study involving apparently healthy young adults between the ages of 18 and 40 years (inclusive) of
Yoruba ethnicity. The target population were the students of Obafemi Awolowo University community, Ile-Ife, Nigeria. Eighty (12 males and 68 females) participants were purposively selected for the study. Twenty participants of blood group $\mathrm{AB}$ were first identified through mass blood group screening process and 20 age and sex- matched participants each of the other three blood groups (A, B and $\mathrm{O}$ ) were also selected for the study Blood sample $(2 \mathrm{~mL})$ was obtained from superficial cubital vein from each participant at resting position after cleaning with $75 \%$ ethyl alcohol using $2 \mathrm{~mL}$ syringe and the sample was dispensed into Sodium EDTA anticoagulant bottle. All sample collections followed standard procedure. A drop of each antisera A, $\mathrm{B}$ and $\mathrm{AB}$ were placed on a clean white tile in three different places marked $\mathrm{X}, \mathrm{Y}$ and $\mathrm{Z}$ respectively. Drops of blood were added to the antisera at points $\mathrm{X}, \mathrm{Y}$ and $\mathrm{Z}$ and mixed with the aid of glass rods. Then, the mixture was rocked gently for 60 seconds and observed for agglutination. The observations at points $\mathrm{X}, \mathrm{Y}$ and $\mathrm{Z}$ were recorded immediately after mixing. The tests were done in duplicates to ensure validity of results. If agglutination was observed at points $\mathrm{X}$ and $\mathrm{Z}$, $\mathrm{Y}$ and $\mathrm{Z}$ and $\mathrm{X}, \mathrm{Y}$ and $\mathrm{Z}$, the participants were classified to belong to blood groups $\mathrm{A}, \mathrm{B}$ and $\mathrm{AB}$, respectively. If no agglutination at points $\mathrm{X}, \mathrm{Y}$ and $\mathrm{Z}$, the participants were classified to belong to blood group $\mathrm{O}$. Agglutination at point $\mathrm{X}$ or $\mathrm{Y}$ or $\mathrm{Z}$ were considered invalid and the test was repeated. Blood pressure (BP) measurement was done by an

*Corresponding author: Asafa MA, Department of Physiological Sciences Obafemi Awolowo University, lle-Ife, Nigeria, Tel: +234(0)8060063353; E-mail: drashafa@gmail.com

Received December 26, 2017; Accepted January 22, 2017; Published January 27, 2018

Citation: Asafa MA, Ogunlade O, Bolarinwa RA (2018) Effect of ABO Blood Group on Blood Pressure Indices among Apparently Healthy Young Adults of Yoruba Ethnicity in Ile-Ife. J Blood Lymph 8: 198. doi:10.4172/2165-7831.1000198

Copyright: ( 2018 Asafa MA, et al. This is an open-access article distributed unde the terms of the Creative Commons Attribution License, which permits unrestricted use, distribution, and reproduction in any medium, provided the original author and source are credited. 
indirect method using a validated Omron digital sphygmomanometer of appropriate cuff size attached to the arm. The BP measurements were taken twice in a sitting position after five minutes of rest. Systolic Blood Pressure (SBP), Diastolic Blood Pressure (DBP) and pulse rate were recorded. Pulse Pressure (PP) was calculated as the difference between SBP and DBP. Mean Arterial Pressure (MAP) was calculated using the formula $\mathrm{MAP}=\mathrm{DBP}+1 / 3(\mathrm{PP})$. Rate Pressure Product (RPP) was calculated as the product of SBP and pulse rate. The data were analyzed by the aids of IBM version 20.0 software using descriptive statistics and cross tabulations. Comparison of means of parameters among the four blood groups ( $\mathrm{A}, \mathrm{B}, \mathrm{AB}$ and $\mathrm{O}$ ) was done using Analysis of Variance (ANOVA) and Duncan Post-hoc test. A p value of $<0.05$ was taken as statistically significant.

\section{Result}

The mean age \pm SD of the participants was $21.50 \pm 3.52$ years. The mean \pm SD of systolic blood pressure $(\mathrm{mmHg})$, diastolic blood pressure $(\mathrm{mmHg})$, pulse rate(beats per minute), Pulse pressure $(\mathrm{mmHg})$, rate pressure product and mean arterial pressure $(\mathrm{mmHg})$ were, $113.05 \pm 10.49,65.06 \pm 10.12,75.33 \pm 12.82,47.99 \pm 9.20,8524.54$ \pm 1708.347 and $81.06 \pm 9.27$, respectively. The highest mean systolic blood pressure, diastolic blood pressure, rate pressure product and mean arterial pressure were found in blood group $\mathrm{O}$ while the highest mean heart rate and pulse pressure were found in blood group $A B$. The relationship between $\mathrm{ABO}$ blood group and $\mathrm{BP}$ indices were not statistically significant ( $\mathrm{p}$-value $>0.05$ ) as shown in Table 1.

\section{Discussion}

The mean systolic (SBP), diastolic blood pressure (DBP) and mean arterial pressure (MAP) were slightly lower to what was reported in a study conducted among 60 young adults in Brazil [13]. The

\begin{tabular}{|c|c|c|c|c|}
\hline $\begin{array}{l}\text { Cardiovascular } \\
\text { Indices }\end{array}$ & Blood group & Parameters (Mean \pm SD) & $\mathbf{F}$ & $p$-value \\
\hline \multirow[t]{4}{*}{ Heart rate $(\mathrm{bpm})$} & A & $74.64 \pm 14.61$ & \multirow{4}{*}{0.132} & \multirow{4}{*}{0.941} \\
\hline & $B$ & $73.77 \pm 13.10$ & & \\
\hline & $\mathrm{O}$ & $75.82 \pm 8.99$ & & \\
\hline & $A B$ & $75.77 \pm 13.43$ & & \\
\hline \multirow[t]{4}{*}{$\mathrm{SBP}(\mathrm{mmHg})$} & A & $111.00 \pm 12.58$ & \multirow{4}{*}{0.776} & \multirow{4}{*}{0.511} \\
\hline & B & $112.68 \pm 9.55$ & & \\
\hline & O & $115.50 \pm 9.66$ & & \\
\hline & $A B$ & $111.14 \pm 11.09$ & & \\
\hline \multirow[t]{4}{*}{$\mathrm{DBP}(\mathrm{mmHg})$} & A & $64.09 \pm 12.67$ & \multirow{4}{*}{1.163} & \multirow{4}{*}{0.329} \\
\hline & $B$ & $66.00 \pm 11.61$ & & \\
\hline & O & $68.91 \pm 8.94$ & & \\
\hline & $A B$ & $63.64 \pm 7.69$ & & \\
\hline \multirow[t]{4}{*}{$\mathrm{PP}(\mathrm{mmHg})$} & A & $46.91 \pm 11.77$ & \multirow{4}{*}{0.040} & \multirow{4}{*}{0.989} \\
\hline & B & $46.68 \pm 8.59$ & & \\
\hline & $\mathrm{O}$ & $46.59 \pm 8.66$ & & \\
\hline & $A B$ & $47.17 \pm 9.22$ & & \\
\hline \multirow[t]{4}{*}{ RPP } & A & $8295.91 \pm 2006.43$ & \multirow{4}{*}{1.241} & \multirow{4}{*}{0.300} \\
\hline & B & $8321.41 \pm 1663.70$ & & \\
\hline & 0 & $8749.82 \pm 1212.54$ & & \\
\hline & $A B$ & $8417.77 \pm 1761.18$ & & \\
\hline \multirow[t]{4}{*}{ MAP $(\mathrm{mmHg})$} & A & $79.73 \pm 11.36$ & \multirow{4}{*}{0.338} & \multirow{4}{*}{0.798} \\
\hline & B & $81.56 \pm 10.19$ & & \\
\hline & $\mathrm{O}$ & $84.44 \pm 8.23$ & & \\
\hline & $A B$ & $79.17 \pm 8.46$ & & \\
\hline
\end{tabular}

SBP: Systolic Blood Pressure; DBP: Diastolic Blood Pressure, MAP: Mean Arterial Pressure; PP: Pulse Pressure; RPP: Rate Pressure Product.

Table 1: Relationship between $A B O$ blood group and some cardiovascular Indices. difference in mean values may be due to racial differences and life style. The highest mean SBP and DBP was found in blood group O which is in support of the report of Kondam and Chandrashekar that the prevalence of hypertension is highest in blood group $\mathrm{O}$ in a study done in 500 known hypertensive patients within the age range of 20-70 years [14]. This is also in support of a report of a study on prevalence of hypertension among post-menopausal women in India within the age range of 45 to 80 years [15]. Increased susceptibility of hypertension in blood group $\mathrm{O}$ may be due to the fact that individuals with blood group O have about 25\% less factor VIII (F VIII) and von Willebrand factor (vWF) in their plasma which was said to predispose them to hypertension [16]. The high protein diet preference for blood group $\mathrm{O}$ as described in 1996 by D'Adamo and Whitney may also be responsible for the highest mean SBP and DBP in this blood group [17]. This is in contrast with blood group $\mathrm{AB}$ reported in studies done among young adults in India. This may be due to varying number of participants in each blood groups used in their studies. It is also in contrast with what was reported among young adults of northeast Bosnia between the age range of 18-23 years with highest mean of SBP in blood group A [18]. The report from this study is also in contrast with the findings of a study done among young adults of a tertiary institution in Mardan by Shams et al. in 2014 which reported blood group A to be at higher risk of developing high blood pressure [19]. This contrast may be due to a high prevalence of blood group A among the study population. RPP is the correlate of myocardiac oxygen consumption, which is the heart work load [20]. The highest mean of RPP was found in blood group $\mathrm{O}$ hence this may put blood group $\mathrm{O}$ at risk of myocardiac infaction. The highest mean of pulse pressure (PP) was in blood group $\mathrm{AB}$. The increase PP has been said to be associated with an increase in central vascular stiffness as described by Franklin in 2006 [21]. Thus, blood group $\mathrm{AB}$ individuals may be predisposed to atherosclerosis.

\section{Conclusion}

This study showed that individuals with blood group $\mathrm{O}$ have highest values of blood pressure indices and may be predisposed to high blood pressure. ABO blood group does not significantly affect blood pressure indices.

\section{Acknowledgement}

The authors appreciate the support received from the entire members of Academic and non-Academic staff of Department of Physiological Sciences, University Health Centre and ECG Unit of Obafemi Awolowo University lle-Ife, Nigeria.

\section{Authors' Contributions}

AMA and $\mathrm{OO}$ designed the study and performed the statistical analysis. AMA, $O O$ and BRA wrote the protocol, drafted the manuscript and managed the literature search. All authors read and approved the final manuscript.

\section{References}

1. Maluf NSR (1954) History of blood transfusion. Journal History of Medicine 9 59-107.

2. Chowdhary S, Sharma V, Chowdhary S (2016) Study of association of ABO blood group with ischemic heart disease. International Journal of Medical Science and Public Health 5: 468-472.

3. Seeley RR, Stephens TD, Tate P (1998) Anatomy and Physiology (4 $4^{\text {th }}$ edn.), The McGraw Hill Companies, Inc., USA, pp: 1098.

4. Shivayogappa ST, Divya R, Paramasivam L, Senthil VM (2016) Association of $\mathrm{ABO}$ and $\mathrm{Rh}$ blood groups with blood pressure: A cross sectional study in South Indian population. Indian Journal of Basic and Applied Medical Research 5: 8-13.

5. Qi L, Cornelis MC, Kraft P, Jensen M, van Dam RM, et al. (2010) Genetic 
Citation: Asafa MA, Ogunlade O, Bolarinwa RA (2018) Effect of ABO Blood Group on Blood Pressure Indices among Apparently Healthy Young Adults of Yoruba Ethnicity in Ile-lfe. J Blood Lymph 8: 198. doi:10.4172/2165-7831.1000198

variants in $\mathrm{ABO}$ blood group region, plasma soluble E-selectin levels and risk of type 2 diabetes. Human Molecular Genetics 19: 1856-1862.

6. Wolpin BM, Kraft P, Gross M, Helzlsouer K, Bueno-de-Mesquita HB, et al. (2010) Pancreatic cancer risk and ABO blood group alleles: results from the pancreatic cancer cohort consortium. Cancer Research 70: 1015-1023.

7. Xie J, Qureshi AA, Li Y, Han J (2010) ABO blood group and incidence of skin cancer. PLoS One 5: e11972.

8. Vital S (2010) Body Temperature, Pulse Rate, Respiration Rate, Blood Pressure. OHSU Health Information. Oregon Health \& Science University, pp: 4-16.

9. Chiatra U, Bhagyalaskshmi K, Vinodini N, Anupama N, Rekha DK, et al. (2014) Comparion of heart rate variability in different $A B O$ blood groups of young adults. International Journal of Medical Science and Public Health 3: 14661469.

10. Iloh GUP, Chuku A, Obiegbu NP, Ofoedu JN, Ikwudinma AO (2013) Frequency of cardiovascular risk factors in adult Nigerians with family history of noncommunicable cardiovascular disease in a primary care clinic of a tertiary hospital in a resource-constrained environment of Eastern Nigeria. American Journal of Health Research 1: 17-25.

11. Chobanian AV, Bakris GL, Black HR, Cushman WC, Green LA, et al. (2003) The seventh report of the Joint National Committee on Prevention, Detection, Evaluation and Treatment of High Blood Pressure: the JNC 7 report. JAMA 289: 2560-2571.

12. Faith CM, Arthur NA (2016) Study of Incidence and Prevalence of Hypertension, Diabetes and Obesity with Blood Type in Postmenopausal Females in Port Harcourt. Saudi Journal of Biomedical Research 1: 22-29.
13. Pizzi OL, Brandao AA, Pozzan R, Magalhaes MEC, de Freitas EV, et al. (2011) Pulse wave velocity in young adults. Study of Rio de Janeiro. Sociedade Brasileira de Cardiologia, pp: 1-6.

14. Kondam A, Chandrashekar M (2012) A study of incidence of hypertension in $\mathrm{ABO}$ and rhesus blood group system. International Journal of Biological Medical Research 3: 1426-1429.

15. Kumar NM, Nadimpalli VR, Vardhan SD (2010) Association of ABO blood groups with Chikungunyavirus. Virology Journal 7: 140.

16. O'Donnell CJ, Nabel EG (2011) Genomics of cardiovascular disease. New England Journal of Medicine 365: 2098-2109.

17. Peter D, Catherine W (1996) Eat Right 4 Your Type: The individual diet solution to staying healthy, living longer \& achieving your ideal weight: 4 blood types, 4 diets. New York; Putnam.

18. Amela H, Edina H, Snježana H, Emir H, Aldijana A, et al. (2017) Blood Group Hypertension and Obesity in the student population of northeast Bosnia And Herzegovina. Nature 62.

19. Shams S, Ajmal H, Khan S, Gul S, Hassan H, et al (2014) Association of ABO blood groups with Blood Pressure among the students of Abdul Wali Khan University Mardan. Journal of Applied Environmental and Biological Sciences 4: 300-303.

20. White WB (1999) Heart rate and the rate-pressure product as determinants of cardiovascular risk in patients with hypertension. American Journal of Hypertension 12: 50S-55S.

21. Franklin SS (2006) Hypertension in older people: part 1. Journal of Clinical Hypertension 8: 444-449. 